\title{
Rhinitis, not to sniff at
}

Already for years we have ample evidence of the severe impact of allergic and non-allergic rhinitis and maybe even more rhinosinusitis on quality of life of our patients and the severe costs these diseases inflict on society ${ }^{(1-4)}$.

Despite this evidence we have difficulty convincing the politicians, health insurance companies and the public that more attention, research and money is needed to prevent these diseases to occur and to further prevent the sometimes serious sequalae of the disease.

In the last few years a number of studies have been performed in real life settings to measure the effect of primary and/or secondary prevention of rhinitis/rhinosinusitis on lower airway disease and the direct and indirect costs of the disease.

Last year the group of Hopkins showed the positive effect of early treatment of rhinosinusitis on the development of asthma and the costs of disease ${ }^{(5,6)}$. In this issue of the journal Droessaert et al. show ${ }^{(7)}$ that immunotherapy for allergic rhinitis is associated with higher control of allergic rhinitis, reduced symptom severity and reduced medication use at 3 years after the onset of treatment. Seventy percent of the patients treated with immunotherapy did not use medication for their allergic rhinitis anymore. Although these are very relevant data, we are still aware that immunotherapy is only given to a minority of the patients with allergic rhinitis ${ }^{(8-10)}$. One of the points that let doctors and patients doubt whether to start immunotherapy is the prediction of the treatment effect. One of the methods to measure immunotherapy effects is the use of provocation tests however these methods have significant methodological issues (11). In this issue of the journal Sakurai et al. show that changes in levels of allergen-specific Th2 cytokine-producing cells and
IL- $10^{+}$Foxp $^{+}$cells could be objective biomarkers to predict the response to SLIT in early phases of the treatment ${ }^{(12)}$. It would be even better to try to predict the response to immunotherapy before the treatment is started and trials to try to achieve that are underway.

A specific symptom of rhinitis and rhinosinusitis that is often underappreciated is the loss of smell ${ }^{(13-16)}$. In earlier issues of the journal and other publications it has been shown that loss of smell is not only relevant in upper airway diseases but is also affected by several neurogenerative diseases and diabetes mellitus and even a primary indicator for the occurrence of Alzheimer's and Parkinson's disease ${ }^{(17-20)}$. Moreover, a relation exists between the olfactory system and the endocrine system with loss of smell in diabetes ${ }^{(21)}$.

Recently, a number of papers point to new treatment options in olfactory loss giving hope to deprived patients. Olfactory training has been shown to be a promising therapeutic approach with which to improve olfactory skills in post-infectious anosmic patients but also in patients with neurogenerative diseases ${ }^{(22-24)}$. Insulin signalling has been implicated in olfactory function and nasally administered insulin can improve smell in post-infectious olfactory patients ${ }^{(21)}$. Now in this issue of the journal, Veyseller et al. show a positive effect of hyperbaric oxygen therapy on olfactory dysfunction in diabetic neuropathy in patients with type 2 diabetes mellitus ${ }^{(25)}$. We have exiting times in rhinologic research and expansion of our field and new treatment options for patients we not so long ago thought we could not help. Now we have to put all our efforts in convincing all but our patients that they need our help.

\section{References}

1. Bachert C, Noergaard Andreasen J. CostEffectiveness of Immunotherapy in the Treatment of Seasonal Allergic Rhinitis: Identifying Product-Specific Parameters of Relevance for Health Care Decision-Makers and Clinicians. Int Arch Allergy Immunol. 2015;168(3):213-7.

2. Cardell LO, Olsson P, Andersson M, Welin KO, Svensson J, Tennvall GR, et al. TOTALL: high cost of allergic rhinitis-a national Swedish population-based questionnaire study. NPJ Prim Care Respir Med. 2016;26:15082.

3. Zuberbier T, Lotvall J, Simoens S, Subramanian SV, Church MK. Economic burden of inadequate management of allergic diseases in the European Union: a GA(2) LEN review. Allergy. 2014;69(10):1275-9.
4. Katotomichelakis M, Tripsianis G, Daniilidi A, Cassimos D, Kourousis C, Vogiatzaki T, et al. Smoking effects on quality of life of allergic rhinitis patients after sublingual immunotherapy. Rhinology. 2015;53(4):325-31.

5. Hopkins C, Andrews P, Holy CE. Does time to endoscopic sinus surgery impact outcomes in chronic rhinosinusitis? Retrospective analysis using the UK clinical practice research data. Rhinology. 2015;53(1):18-24.

6. Hopkins C, Rimmer J, Lund VJ. Does time to endoscopic sinus surgery impact outcomes in Chronic Rhinosinusitis? Prospective findings from the National Comparative Audit of Surgery for Nasal Polyposis and Chronic Rhinosinusitis. Rhinology. 2015;53(1):10-7.

7. Droessaert V, Timmermans M, Dekimpe $E_{\text {, }}$
Seys S, Ceuppens JJ, Fokkens WJ, et al. Reallife study showing better control of allergic rhinitis by immunotherapy than regular pharmacotherapy. Rhinology. 2016; 54(3): 214-20.

8. Cornelis $M$, Rombaux $P$, Jorissen M, Hellings PW. Nationwide survey on immunotherapy practice by ENT specialists. Rhinology. 2014;52(1):72-7.

9. Petalas K, Durham SR. Allergen immunotherapy for allergic rhinitis. Rhinology. 2013;51(2):99-110.

10. Kariyawasam HK, Rotiroti G, Robinson DS. Sublingual immunotherapy in allergic rhinitis: indications, efficacy and safety. Rhinology. 2013;51(1):9-17.

11. Graf N, Dinkel B, Rose $H$, Hothorn LA, Gerhard D, Johansen P, et al. A critical 
appraisal of analyzing nasal provocation test results in allergen immunotherapy trials. Rhinology. 2014;52(2):137-41.

12. Sakurai $D$, Yonekura $S$, linuma $T$, Sakurai $T$, Morimoto $Y$, Mita $Y$, et al. Sublingual immunotherapy for allergic rhinitis: subjective versus objective tools to evaluate its success. Rhinology. 2016; 54(3): 221-30.

13. Hopkins C, Philpott C, Crowe S, Regan S, Degun A, Papachristou I, et al. Identifying the most important outcomes for systematic reviews of interventions for rhinosinusitis in adults: working with Patients, Public and Practitioners. Rhinology. 2016;54(1):20-6.

14. Vandenhende-Szymanski C, Hochet B, Chevalier D, Mortuaire G. Olfactory cleft opacity and CT score are predictive factors of smell recovery after surgery in nasal polyposis. Rhinology. 2015;53(1):29-34.

15. Minwegen F, Thomas JP, Bernal-Sprekelsen M, Dazert S, Minovi A. Predictive value of disease severity on self-reported rating and quantitative measures of olfactory function outcomes after primary endoscopic sinus surgery. A prospective study. Rhinology. 2014;52(4):437-43.
16. Lotsch J, Reither N, Bogdanov V, Hahner A, Ultsch A, Hill K, et al. A brain-lesion pattern based algorithm for the diagnosis of posttraumatic olfactory loss. Rhinology. 2015;53(4):365-70.

17. Goektas O, Schmidt F, Bohner G, Erb K Ludemann L, Dahlslett B, et al. Olfactory bulb volume and olfactory function in patients with multiple sclerosis. Rhinology. 2011:49(2):221-6.

18. Hidalgo J, Chopard G, Galmiche J, Jacquot $L$, Brand G. Just noticeable difference in olfaction: a discriminative tool between healthy elderly and patients with cognitive disorders associated with dementia. Rhinology. 2011;49(5):513-8.

19. Cavaco S, Goncalves A, Mendes A, Vila-Cha N, Moreira I, Fernandes J, et al. Abnorma Olfaction in Parkinson's Disease Is Related to Faster Disease Progression. Behav Neurol. 2015;2015:976589.

20. Godoy MD, Voegels RL, Pinna Fde R Imamura R, Farfel JM. Olfaction in neurologic and neurodegenerative diseases: a literature review. Int Arch Otorhinolaryngol. 2015;19(2):176-9.
21. Schopf V, Kollndorfer K, Pollak M, Mueller CA, Freiherr J. Intranasal insulin influences the olfactory performance of patients with smell loss, dependent on the body mass index: A pilot study. Rhinology. 2015;53(4):371-8

22. Konstantinidis I, Tsakiropoulou E, Constantinidis J. Long term effects of olfactory training in patients with postinfectious olfactory loss. Rhinology. 2016 Jun;54(2):170-5.

23. Mori E, Petters W, Schriever VA, Valder C, Hummel T. Exposure to odours improves olfactory function in healthy children. Rhinology. 2015;53(3):221-6.

24. Haehner A, Tosch C, Wolz M, Klingelhoefer L, Fauser $M$, Storch $A$, et al. Olfactory training in patients with Parkinson's disease. Plos one. 2013;8(4):e61680.

25. Veyseller B, Dogan R, Yenigun A, Aksoy $F_{\text {, }}$ Tugrul S, Dogan EE, et al. Hyperbaric oxygen therapy of olfactory dysfunction in diabetic neuropathy with type 2 diabetes mellitus and a new definition "Diabetic Olfactopathy" Rhinology. 2016; 54(3): 27377

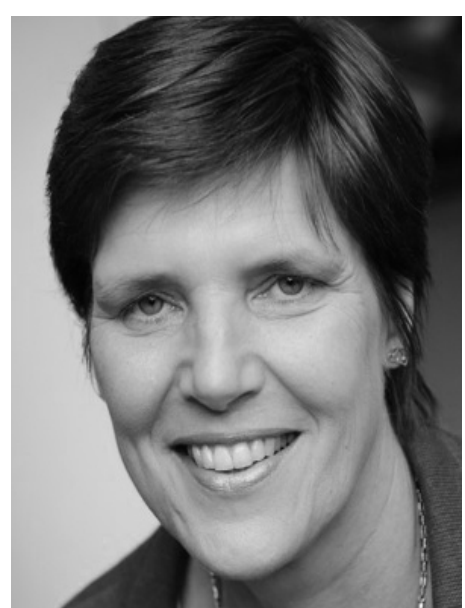

Wytske J. Fokkens, Editor-in Chief Amsterdam, the Netherlands 